\title{
Use of hydrated material for dynamic seal faces in shaft seal
}

\author{
Yuki YOSHIOKA*, Takuro HONDA*, Keiji KASAMURA**, Yuta NAKASHIMA***, \\ Hidehiko HIGAKI**** and Yoshitaka NAKANISHI*** \\ *Graduate School of Advanced Science and Technology, Kumamoto University \\ 2-39-1 Kurokami, Chuo-ku, Kumamoto 860-8555, Japan \\ ** Faculty of Engineering, Kumamoto University \\ 2-39-1 Kurokami, Chuo-ku, Kumamoto 860-8555, Japan \\ E-mail: y-naka@mech.kumamoto-u.ac.jp \\ ***Faculty of Advanced Science and Technology, Kumamoto University \\ 2-39-1 Kurokami, Chuo-ku, Kumamoto 860-8555, Japan \\ ${ }^{* * * *}$ Faculty of Life Science, Kyushu Sangyo University \\ 2-3-1 Matsukadai, Higashi-ku, Fukuoka 813-0003, Japan
}

Received: 25 December 2018; Revised: 5 March 2019; Accepted: 7 April 2019

\begin{abstract}
In ocean current and tidal power generation systems, the rotating shaft, which connects the turbine in water phase and the generation system in air phase, experiences a variety of shaft speeds and high water-pressure conditions. The shaft seal is required to separate water and air with a rotating shaft, which should guarantee both a low frictional torque and a low leakage of water. Conventional shaft seals realize the low frictional torque by operating in a hydrodynamic lubrication mode at the dynamic seal face. However, the dynamic seal face suffers to form rich lubrication film against low speed shaft in water environment. Therefore, a hydrated seal ring was proposed for use in the dynamic seal faces to realize the boundary lubrication. The hydrated seal ring made of a polyvinyl formal (PVF) was adopted. Two types of shaft seals using PVF seal ring were designed, which had the similar structure to oil seals or mechanical seals. The design scheme was validated using verification tests in which the shaft rotation speed was varied from 5000 to -5000 revolutions per minute under a water pressure of $0.5 \mathrm{MPa}$. The hydrated seal ring can be further improved by avoiding deformation of the hydrated seal ring to inhibit the clearance flow in the dynamic seal face. However, it needed to consider the surface profile of the ceramics surface used as a counterface of the hydrated seal ring because the heat generation at the dynamic seal face might be occurred, which changes the material property of the hydrated seal ring.
\end{abstract}

Keywords : Shaft seal, Hydrated material, Polyvinyl formal, Dynamic seal face, Leakage

\section{Introduction}

Ocean current and tidal power are promising renewable energy sources. To capitalize these resources, an ideal power generation system has been proposed, in which a rotating shaft with a turbine, dynamo, and ancillary systems are installed in the same straight line below the sea level. In such a generation system however, an excellent shaft seal is required in order to increase the separation ability between the water and air phases and to decrease the frictional loss (Topaloglu et al., 2016; Nakanishi et al., 2014; Chikaura rt al., 2014).

Two types of well-known shaft seals are used as mechanical elements (Bock et al., 2003). One is an oil seal as shown in Fig. 1 (a), and the other is a mechanical seal as shown in Fig. 1 (b). Oil seals consist of a rubber seal ring that slides against the shaft surface (Watt, 1973). They are often used in oil environment and at high shaft speed, and their dynamic seal faces are in hydrodynamic lubrication mode. On the other hand, the water-air separation provided by oil seals are not expected to be perfect because the lubrication film is easily formed in oil environment, however, that is likely to suffer to be formed in water environment and the dynamic seal face cause a lubrication failure. Mechanical seals consist of two main components which are a primary ring and a mating ring. The primary ring rotates with a shaft and the mating ring is fixed to the mechanical body. The primary ring is axially pressed against the mating ring. Mechanical seals are 
also used at the high shaft speed, and their dynamic seal faces are in hydrodynamic lubrication mode.

In order to reduce water leakage and frictional loss, the presence of water should be realized to promote the formation of an effective boundary lubricating film in a dynamic seal face. Therefore, a hydrophilic material should be used for sliding materials, and polyvinyl formal (PVF) was proposed as seal ring materials. It is a crosslinked polymer of polyvinyl alcohol (PVA), and can compensate for the drawback of the PVA hydrogel.

In previous study, some types of shaft seals have been specially designed to separate water and air at a low frictional torque. The proposed shaft seal had two hydrated seal rings fabricated from PVF and injected an aqueous solution of Polyethylene glycol (PEG) (Honda et al., 2018a; Nakanishi et al., 2016). The shaft seal exhibited a lower frictional torque than oil and mechanical seals. The prevention of water leakage from the water phase to the air phase was also confirmed for water pressure up to $0.8 \mathrm{MPa}$ (Honda et al., 2015, 2018b). Furthermore, Verification tests performed in a river demonstrated that the shaft seal satisfied the requirements for hydropower generation, which include high waterproof performance and low friction (Honda et al., 2015). Since then, the shaft seal has been improved to have a simplified configuration without using the PEG solution, and this seal was attempted for use as a mechanical element of pumps (Honda et al., 2018b; Nakanishi et al., 2017, 2018).

In this study, two types of shaft seals used the seal ring made of the PVF were proposed. One was designed to prevent water leakage between the shaft. The other was designed to prevent water leakage between the seal ring and a ceramic ring used as the conterface of seal ring. These shaft seals were designed to satisfied that the dynamic seal face was in boundary lubrication mode. The possibility of their application in power generation systems was investigated.

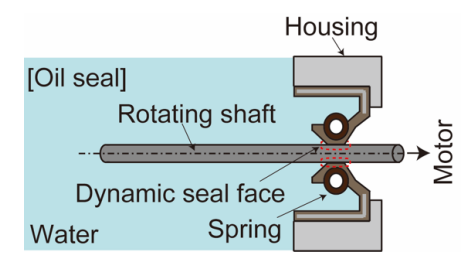

(a)

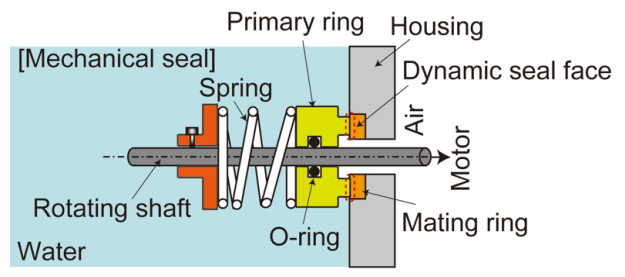

(b)

Fig. 1 Two types of dynamic seal faces; (a) Oil seal, (b) Mechanical seal.

\section{Materials and Methods}

\subsection{Configuration of shaft seal}

Figure 2 shows the two types of shaft seals used for testing. For Type-A, a hydrated seal ring made of polyvinyl formal (PVF) was attached to a rotating shaft (Nakanishi et al., 2009). The ring was fixed with a mechanical body via a holder jig. The shaft had a diameter of $8 \mathrm{~mm}$ and was fabricated using stainless steel (SUS304-JIS). A surface roughness (Ra) of $0.02 \mu \mathrm{m}$ was provided on the rotating shaft by using a conventional lapping method. A dynamic seal face (frictional area) was located between the surfaces of the hydrated seal ring and the rotating shaft.

For Type-B, the hydrated seal ring made of PVF was fixed with a holder jig. The holder jig was connected to the shaft (SUS304-JIS) with a diameter of $8 \mathrm{~mm}$. The surface roughness (Ra) of $0.02 \mu \mathrm{m}$ was provided via an O-ring. The seal ring rotated with the shaft and was pressed to the ceramic ring, which was fixed with a mechanical body via a spring. The dynamic seal face was located between the surfaces of the seal and ceramic rings.

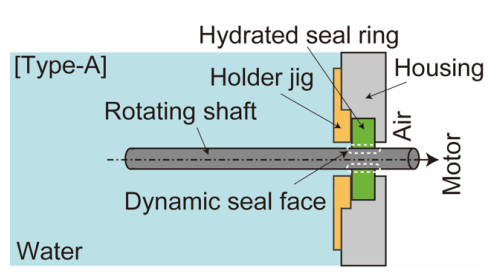

(a)

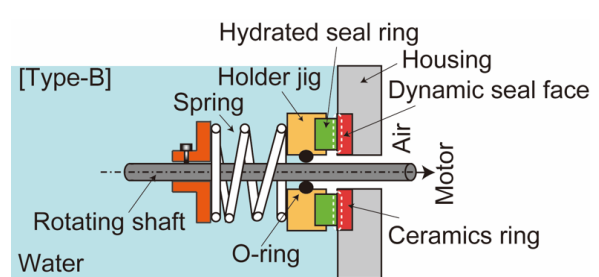

(b)

Fig. 2 Schematic illustrations of shaft seals with the hydrated seal rings made of a polyvinyl formal (PVF); (a) Type-A, (b) Type-B. 


\subsection{Preparation of hydrated seal ring}

Figure 2 shows the dimensions and images of the hydrated Type-A and Type-B seal rings. The preparation process is summarized in Fig. 3. Polyvinyl alcohol (PVA), which is one of the few polymers with hydrophilic properties, was the base material of the PVF (Nakanishi et al., 2009). A PVA solution was prepared by employing the method of agitation to mix partially hydrolysed PVA (with a molecular weight of 1000) and pure water (ion exchange resin processing) for 48 $\mathrm{h}$ at $50{ }^{\circ} \mathrm{C}$ to hydrate the PVA. To initiate condensation polymerization between the PVA molecules (i.e., crosslink formation), $\mathrm{HCHO}$ was added to the PVA mixture as a crosslinker, following the addition of $\mathrm{H}_{2} \mathrm{SO}_{4}$ as a catalyser. This chemical reaction facilitated improved mechanical strength and wear resistance in the PVA. The solution was then poured into a mound of polytetrafluoroethylene (PTFE). After allowing the mound to set for $18 \mathrm{~h}$ at $25^{\circ} \mathrm{C}$, neutralization was performed using $\mathrm{NaOH}$ and water washing to remove the $\mathrm{HCHO}$ in the hydrated material.
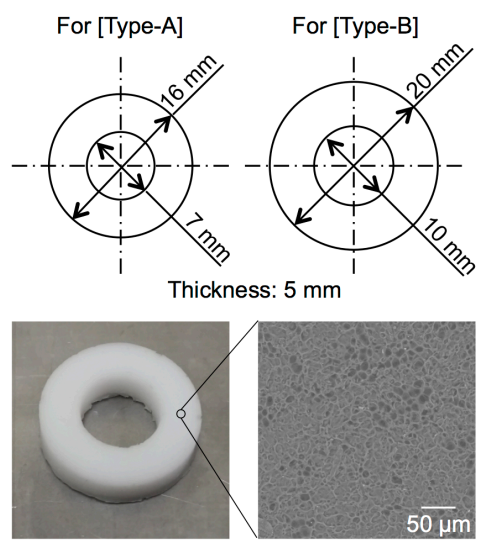

Fig. 3 Dimensions and images of hydrated seal rings.

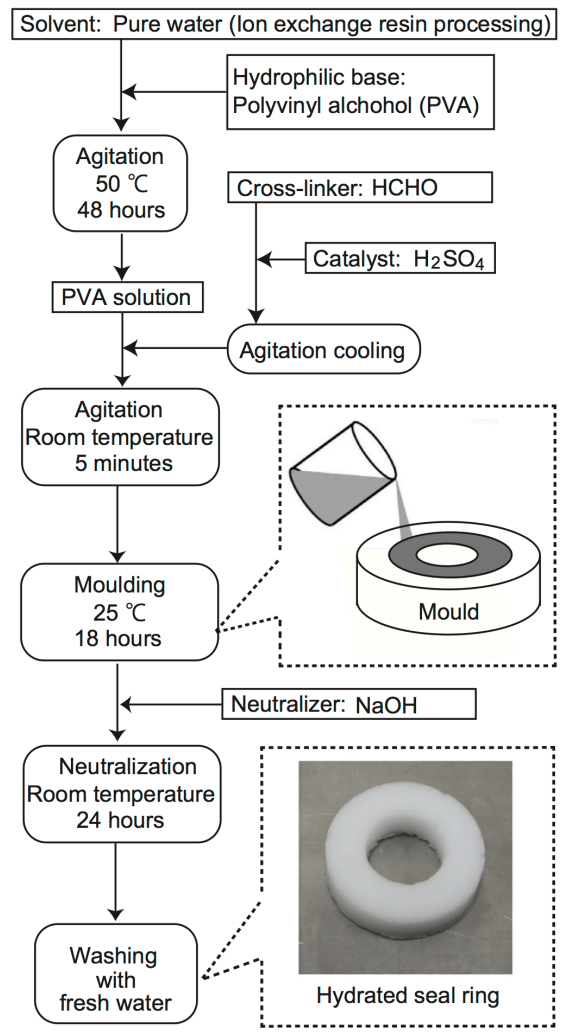

Fig. 4 Process of preparation of hydrated seal ring.

\subsection{Preparation of ceramics ring}

Four types of ceramics rings were prepared as counterface rings to the hydrated seal ring for Type-B (Fig. 2). Two rings were made of a steatite ceramic, one with and one without a conventional lapping process (Fig. 5 (a)). The other two rings were made of an alumina ceramic, one with and one without the conventional lapping process (Fig. 5 (b)). The two ceramics rings were lapped their surfaces by using a wet abrasive paper (1000, 1500 and 2000 grit) and polished their surfaces by using the abrasive paste (Pica paste, AISHI DENTAL Lab., Japan). It was found that the lapping processing reduced the surface roughness of each ceramic rings. 

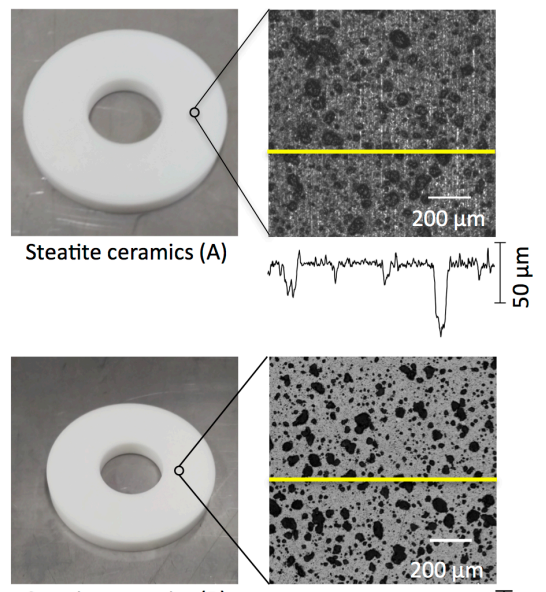

Steatite ceramics (B)

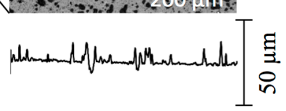

(a)
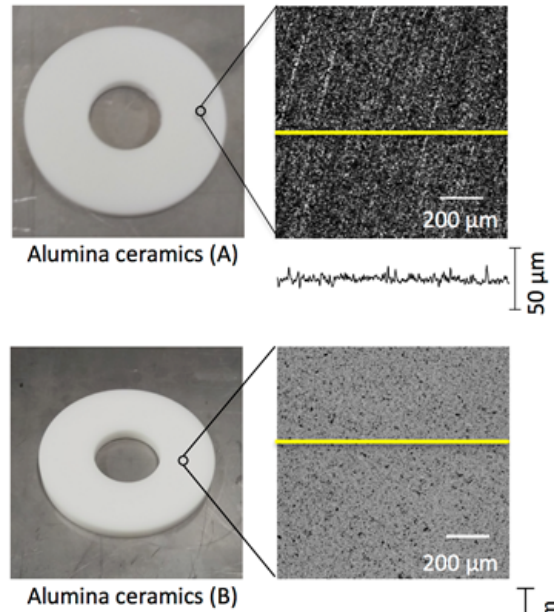

「星

(b)

Fig. 5 (a) Ceramic ring made of steatite ceramics as counterface material to hydrated seal ring for Type-B, (b) Ceramic ring made of alumina ceramics as counterface material to hydrated seal ring for Type-B

\subsection{Testing device and testing conditions}

Each shaft seal (Fig. 2) was attached to the experimental setup (Fig. 6). Purified water at room temperature in a chamber was pressurized to 0.5 MPa. The shaft was rotated by an AC servomotor (NX-45, Oriental Motor Co. Ltd., Japan). Figure 7 shows the rotating conditions of the shaft during the test. The rotation speed of the shaft was changed from 5000 to -5000 revolutions per minute in $24 \mathrm{~h}$, and the cycle was repeated during the test. The frictional torque caused by the shaft seal was calculated according to the relationship between the rated torque of the motor and the power consumption, and the mean value of the frictional torque was calculated. The leaked water was collected in a pan, and the mean leakage of water during testing $(\mathrm{mL} / \mathrm{h})$ was calculated.

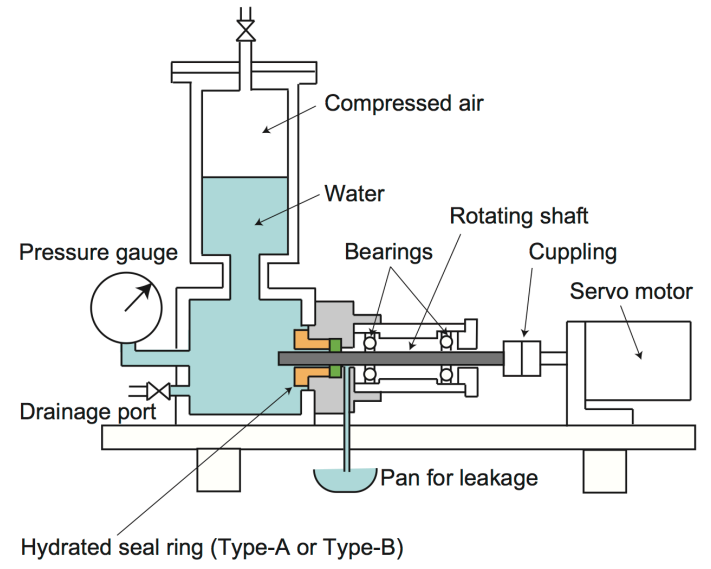

Fig. 6 Schematic illustration

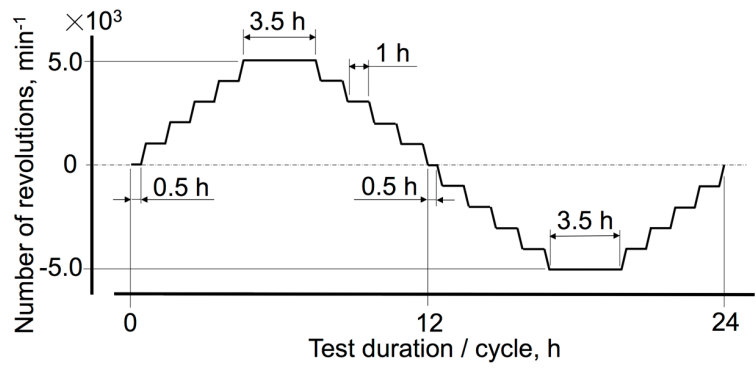

Fig. 7 Rotating conditions of shaft during test. One rotating cycle was $24 \mathrm{~h}$. This cycle was repeated during test.

of shaft seal performance testing device.

\section{Results}

Figure 8 (a) shows the frictional torque and water leakage in the hydrated seal ring (Type-A). The water leakage was at a low level during the test. However, because abrupt and nonnegligible water leakage was observed at $340 \mathrm{~h}$, the experiment was terminated. 
Figure 8 (b) shows the frictional torque and water leakage in the hydrated seal rings (Type-B \& steatite ceramic rings). The frictional torque of the hydrated seal was higher than that of the Type-A (Fig. 8 (a)); however, its water leakage was lower than that of Type-A. The duration time could be extended than the Type-A. The experiment using the steatite ceramics (A) was terminated at $504 \mathrm{~h}$ because abnormal noise at the point of contact of the holder jig and the ceramic ring could not be ignored. While using the steatite ceramics (B), water leakage was not detected; however, the frictional torque increased and duration time was shortened $(441 \mathrm{~h})$.

Figure 8 (c) shows the frictional torque and water leakage in the hydrated seal ring (Type B \& alumina ceramic rings). By using the alumina ceramic ring (A), the duration time could be extended to more than that of the steatite ceramic ring (Fig. 8(b)), although the frictional torque was nearly the same in both cases. However, because nonnegligible water leakage was observed at $576 \mathrm{~h}$, the experiment was terminated. While using the alumina ceramic ring (B), water leakage was not detected; however, the duration time was shortened (429 h).

The hydrated seal rings after the tests are shown in Fig. 9. In the Type-A hydrated seal ring, the porous structure, which could be observed in the original PVF (Fig. 2), was maintained. However, plastic deformation of the seal ring was observed. In the Type-B seal ring with a steatite ceramic ring (A), the porous structure of the PVF could not be observed, and aggregates with worn materials were detected on the dynamic seal face of the ring. The decrease in surface roughness of a steatite ceramic ring could lead to plastic flow on the PVF ring surface (Type-B \& Steatite ceramics (A)). It was noted that for the Type-B seal ring with an alumina ceramic ring, the material property and colour had changed, and one seal ring was completely destroyed.

Figure 10 (a) shows the steatite ceramic rings after the tests. The concave area, derived from wear by direct contact with the holder jig, was observed in the steatite ceramic ring. The other dynamic seal faces were not changed in comparison with the surfaces before the tests. Figure 10 (b) shows the alumina ceramic rings after the tests. The concave area, derived from wear by direct contact with the holder jig, was observed in the alumina ceramic ring (B). The dynamic seal faces on the alumina ceramic ring (A) did not change in comparison with the surfaces before the tests. Nevertheless the colour on the dynamic seal faces on the alumina ceramic ring (B) changed.

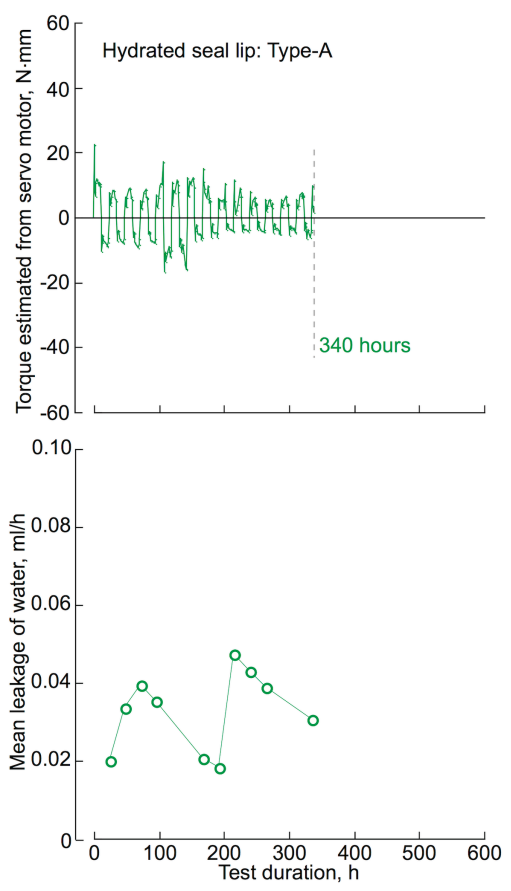

(a)

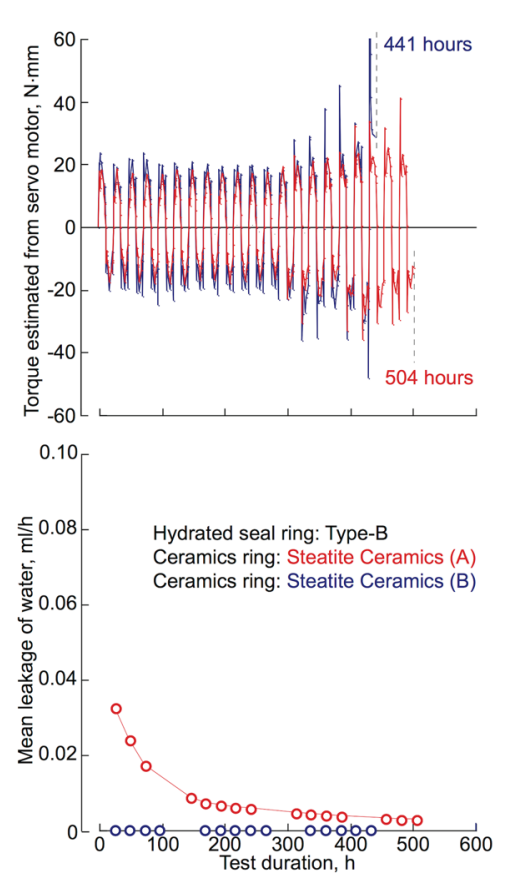

(b)

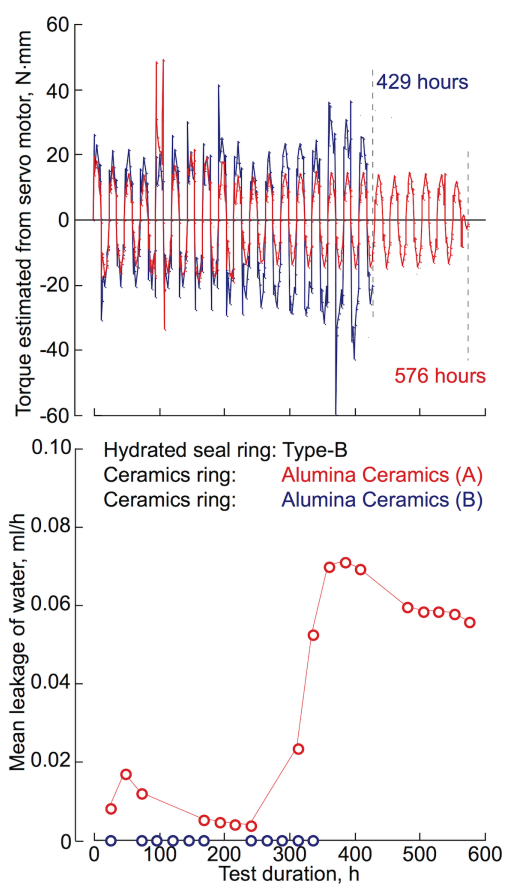

(c)

Fig. 8 (a) Frictional torque and water leakage in hydrated seal ring (Type A), (b) Frictional torque and water leakage in hydrated seal ring (Type B). Steatite ceramics (A) or (B) were used to produce the counterface ring, (c) Frictional torque and water leakage in hydrated seal ring (Type B). Alumina ceramics (A) or (B) were used to produce the counterface ring. 


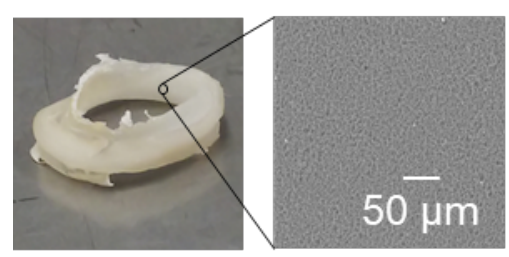

Type-A
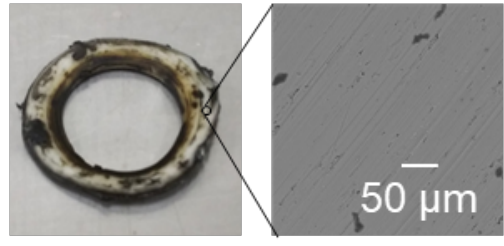

Type-B \& Steatite ceramics $(A)$
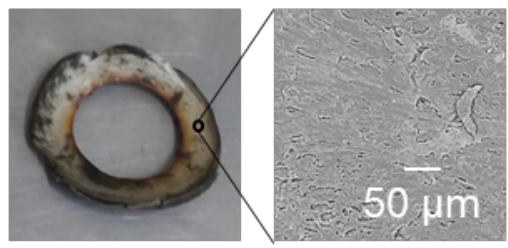

Type-B \& Steatite ceramics (B)

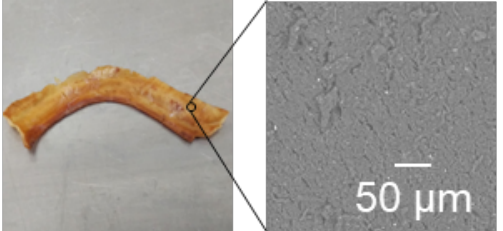

Type-B \& Alumina ceramics $(A)$

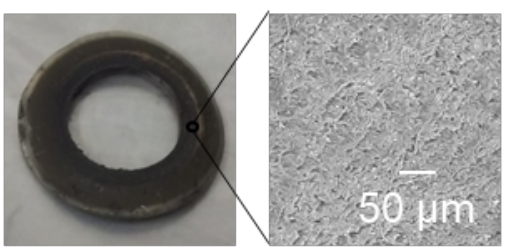

Type-B \& Alumina ceramics $(B)$

Fig. 9 Hydrated seal rings after test.
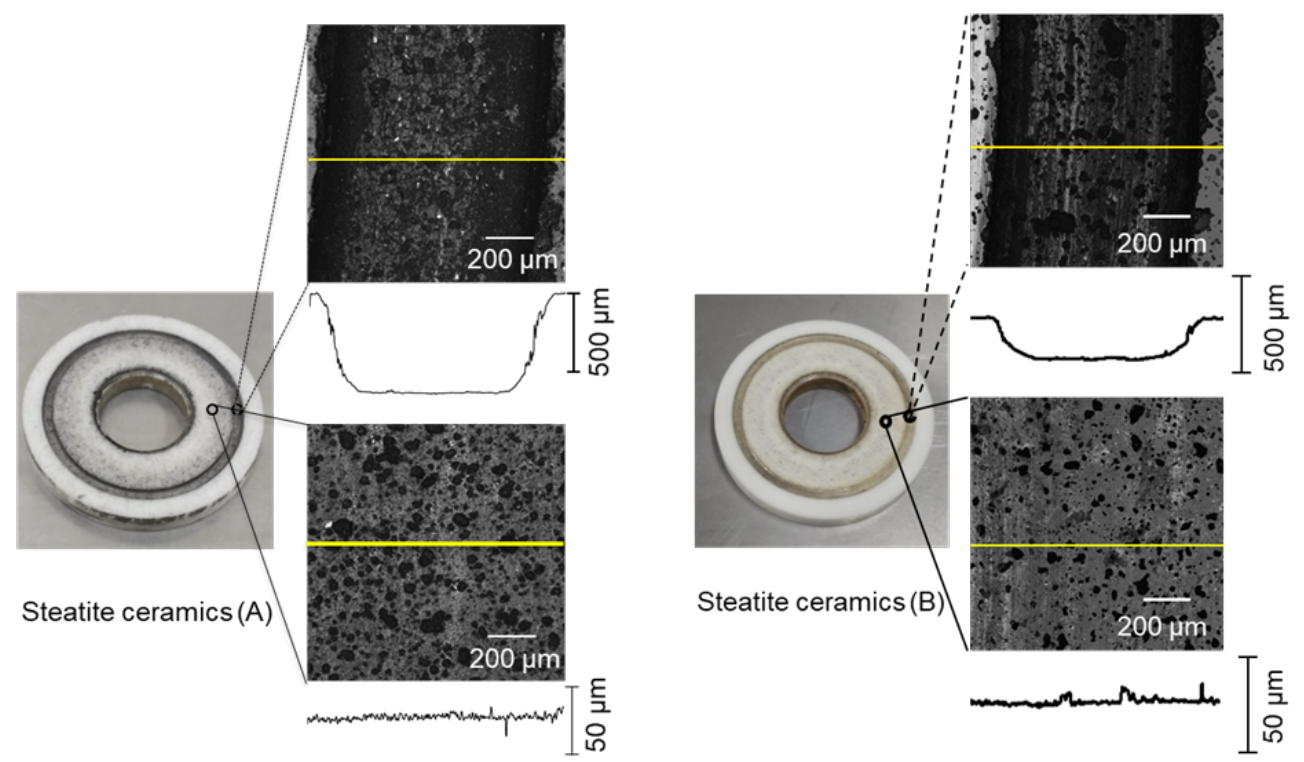

(a)

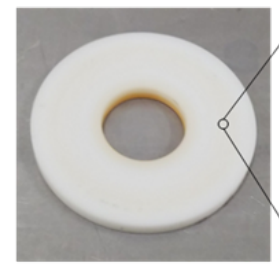

Alumina ceramics $(\mathrm{A})$

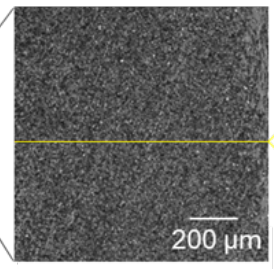

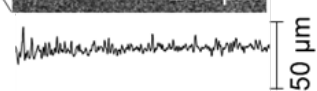

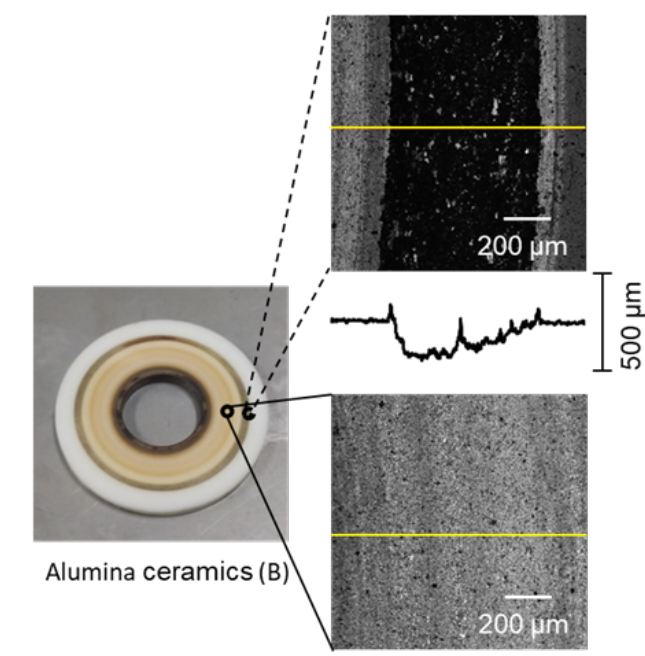

(b)

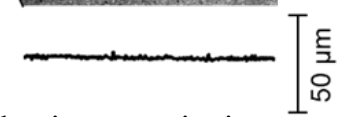

Fig. 10 Ceramic ring after test; (a) Steatite ceramic rings, (b) Alumina ceramic rings. 


\section{Discussion}

A shaft seal of Type-A showed a lower frictional torque than that of Type-B because the diameter of the seal ring of Type-A was smaller than that of Type-B. In addition, the contact pressure caused by the seal ring of Type-A was smaller than that of Type-B because the seal ring of Type-A was simply pressed into the housing. However, the test duration of Type-A was shorter than Type-B. From the observation of the seal ring of Type-A after test, PVF seal ring with low elasticity was deformed by water pressure and allowed clearance for leakage path.

To avoid the clearance flow of water between dynamic seal faces owing to the plastic deformation of the hydrated seal ring (Type-A), Type-B, which had the mechanism of a mechanical seal, was also proposed. The PVF seal ring rotates with the shaft, and the ceramic ring is fixed to the mechanical body as a stationary part. The frictional torque of type-B without the lapping process was low as compared to that with the lapping process. On the other hand, the shaft seals of Type-B used ceramics rings with a lapping process showed little water leakage. This was thought that the clearance between the seal ring and the ceramic ring was closed because the surface roughness of the ceramic ring was smaller than that without the lapping process, and the seal ring was tightly attached to the ceramic ring.

The difference in the elastic modulus between the seal ring and the ceramic counterface might accelerate wear in the seal ring. The highly porous structure of the steatite ceramics promoted hydrated lubrication because water is supplied to the dynamic seal face. However, this porous structure (roughened surface) led to accelerated wear in the PVF seal ring. The surface profile of the alumina ceramics had a smooth surface in comparison to the steatite ceramics. Thus, suppressed wear of the ring might be expected. On the other hand, the smooth surface without a porous structure could not provide water to the dynamic seal face. The lubricating characteristics might cause the generation of heat between dynamic seal faces, which might change the material property of the PVF seal ring and damaged the PVF seal ring.

\section{Conclusions}

Two types of shaft seals which operate in a boundary lubrication were designed using hydrated seal rings made of polyvinyl formal (PVF) for use in ocean current or tidal power generation systems. Type-A showed a low frictional torque with a low water leakage. The duration time of Type-B could be extended more than that of Type-A. Type-B used ceramics rings with a lapping process were recorded the minimum amount of water leakage. However, the surface profile of the ceramic surface should be considered to control water supply to the sliding surface, because the profile influences the wear of the seal ring or the heat generation of the dynamic seal face.

\section{References}

Bock E, Vogt R, Schreiner P. New radial shaft seal concept for sealing hydraulic pump and motors. Seal Technol, Vol.11, (2003), pp.6-10.

Chikaura H, Oka Y, Nakashima Y, Nakanishi Y. Development of a new type of seal system for use in ocean current or tidal power generation. Proc 16th Power Electron Motion Control Conf Expo (PEMC2014), (2014), pp.828-832, DOI: 10.1109/EPEPEMC.2014.6980600.

Honda T, Kasamura K, Nakashima Y, Higaki H, Nakanishi Y. Low-friction shaft seal composed of bio-inspired materials covering low-speed range under water environment. Proc Inst Mech Eng Part J: J Eng Tribol, Vol.1, (2018a), pp.3642, DOI: $10.1177 / 1350650117738702$.

Honda T, Kasamura K, Nakashima Y, Nakanishi Y, Higaki H. An ideal generation system for streamflow, tidal and ocean currents-Installation of biomimetic sealing system. 2015 IEEE Int Conf Renew Energy Res Appl (ICRERA), (2015), pp.596-599, DOI: 10.1109/ICRERA.2015.7418483.

Honda T, Nakashima Y, Higaki H, Nakanishi Y, Fiber reinforcement of hydrophilic materials for a low-torque shaft seal in water environment. Mech Eng Lett, Vol.4, 17-00590 (2018b), DOI: 10.1299/mel.17-00590.

Nakanishi Y, Oka Y, Sanderson J, Honda T, Kasamura K, Nakashima Y, Higaki H. Biomimetic sealing system with hydrated materials for ocean current or tidal power generation. 2014 IEEE Int Conf Renew Energy Res Appl (ICRERA), (2014), pp.755-759, DOI: 10.1109/ICRERA.2014.7016486.

Nakanishi Y, Honda T, Nakashima Y, Higaki H. Shaft seal for separation of water and air with low frictional torque. Tribol Int, Vol.94, (2016), pp.437-445.

Nakanishi Y, Honda T, Kasamura K, Nakashima Y, Higaki H. Bio-inspired seal lip for application in electric vehicle 
coolant pumps. Mech Eng Lett Vol.4, 17-00654 (2018), DOI: 10.1299/mel.17-000654.

Nakanishi Y, Honda T, Nakashima Y, Nakano K, Kondo K, Higaki H. Bio-inspired shaft seal in coolant pump for electric vehicles. 2016 IEEE Int Conf Renew Energy Res Appl (ICRERA), (2017), pp.112-117, DOI: 10.1109/ICRERA.2016.7884449.

Nakanishi Y, Takashima T, Higaki H, Shimoto K, Umeno T, Miura H, Iwamoto Y. Development of biomimetic bearing with hydrated materials. J Biomech Sci Eng, Vol.4, (2009), pp.249-264.

Topaloglu I, Nakanishi Y, Korkmaz F, Nakashima Y. Axial flux permanent magnet generator with low cogging torque for maintenance free under water power generating system. Int J Renew Energy Res, Vol.2, (2016), pp.510-519.

Watt SV. Material selection criteria for water lubrication. Wear, Vol.25, (1973), pp.139-153. 